\title{
Low postabsorptive net protein degradation in male cancer patients: Lack of sensitivity to regulatory amino acids?
}

\author{
EGGERT HOLM $^{1}$, WULF HILDEBRANDT $^{2,3}$, RALF KINSCHERF $^{2,3}$ and WULF DRÖGE ${ }^{2}$ \\ ${ }^{1}$ Department of Pathophysiology, Medical Clinic 1 Mannheim, University of Heidelberg, D-68167 Mannheim; \\ ${ }^{2}$ Division of Immunochemistry (Redox Physiology and Aging Research), Deutsches Krebsforschungszentrum, \\ Im Neuenheimer Feld 280, D-69120 Heidelberg, Germany
}

Received May 12, 2006; Accepted September 7, 2006

\begin{abstract}
Autophagic (lysosomal) and proteasomic protein degradation are important regulatory mechanisms in the homeostasis of muscle mass, that may be profoundly disturbed in cancer and other wasting syndromes. Due to the inhibiting effect of amino acids and insulin, net proteolysis is restricted to the fasted state, and in autophagy certain amino acids have been identified as 'regulatory' in the rat, including leucine, tyrosine, phenylalanine, methionine, and histidine (i.e. LYFMH). The present cross-sectional study assessed postabsorptive net protein catabolism in male cancer patients as well as in healthy male volunteers, to analyse its relation to such 'regulatory amino acids'. Postabsorptive amino acid exchange rates across the leg were determined in patients with gastrointestinal cancer (GIC, $\mathrm{n}=47$ ) or renal cell carcinoma (RCC, $n=15)$, age-matched $(n=33)$, and young male control subjects $(n=42)$. Both groups of cancer patients revealed a significantly lower postabsorptive net protein catabolism than control subjects. Furthermore, in the control subjects, the postabsorptive net protein catabolism was found to be inversely and significantly correlated with the arterial concentrations of the 8 amino acids YSHMFGI and L which include 5 of the 'regulatory amino acids'. Cancer patients, in contrast, revealed no such significant correlations. These results may indicate i) that postabsorptive net protein catabolism in skeletal muscle of healthy subjects may be sensitive to amino acids which reportedly regulate autophagy and ii) that such amino acidsensitive mechanism of protein catabolism may be disturbed in cancer patients.
\end{abstract}

Correspondence to: Dr Wulf Hildebrandt, Deutsches Krebsforschungszentrum, Division of Immunochemistry, Im Neuenheimer Feld 280, D-69120 Heidelberg, Germany

E-mail: wulf-hildebrandt@t-online.de

Present address: ${ }^{3}$ Anatomy and Developmental Biology, Medical Faculty Mannheim, University of Heidelberg, D-68167 Mannheim, Germany

Key words: autophagic protein degradation, postabsorptive protein catabolism, amino acid-sensitive protein catabolism, cancer patients, catabolism

\section{Introduction}

Autophagic (lysosomal) together with proteasomic protein breakdown has been recognized as an intracellular catabolic mechanism, that balances protein synthesis and allows for homeostasis of e.g. skeletal muscle protein content and mass. Autophagy, an evolutionary conserved pathway of all eukaryotic cells, contributes to long-lived protein degradation as well as organelle turnover $(1,2)$ and has a pivotal role in health and disease. During (macro)autophagy cytoplasmic material is engulfed by intracellular membranes from endoplasmic reticulum, which thereby form vesicles (autophagosomes) and eventually fuse with lysosomes. By targeting the autophagy gene beclin 1 (bec-1) in the Daf-2 (e1370) mutant of C. elegans, i.e. a well established model of aging, autophagy was shown to be essential for life span extension (3). This positive effect of autophagy is tentatively explained by its role in the homeostatic control of free amino acid concentrations and mitochondrial turnover. At least in Saccharomyces cerevisiae and Dictyostelium discoideum, autophagy was shown to be essential for cell survival at times of limited amino acid availability (4-6). By degrading degenerated organelles, including mitochondria, autophagy also plays an important role in the maintenance of cellular integrity $(2,7,8)$. It also plays a role in the turnover of Alzheimer's precursor protein (reviewed in refs. 9,10).

Autophagic and proteasome activity are subjected to nutritional and hormonal control, e.g. through insulin and amino acids. Amino acids were shown to inhibit autophagic protein catabolism in liver (11-15) and skeletal muscle cells (16-20). In experiments on rat liver, Mortimore and colleagues identified leucine, phenylalanine, tyrosine, glutamine, proline, histidine, tryptophane, and methionine as the effective amino acids and proposed the term 'regulatory amino acids' $(11,12,21)$. More recent studies have shown that autophagy is inversely correlated with protein synthesis at the translational level as schematically illustrated in Fig. 1. Amino acids were reported to upregulate the mammalian target of rapamycin (mTOR or FRAP) (22-24), to stimulate p70 S6 kinase $(25,26)$, and to exert, in addition, a direct inhibitory effect on autophagic activity through an mTOR-independent signaling pathway $(15,20)$. It has been suggested that a decrease in amino acid concentrations may also stimulate the chymotrypsin-like activity of the proteasome, but the effects were relatively small 
Table I. Metabolite exchange rates ${ }^{\mathrm{a}}$ in cancer patients and control groups.

\begin{tabular}{|c|c|c|c|c|c|}
\hline & $\begin{array}{l}\text { GI-cancer } \\
\text { patients }\end{array}$ & $\begin{array}{c}\text { Renal cell } \\
\text { cancer patients }\end{array}$ & $\begin{array}{c}\text { Total cancer } \\
\text { patients }\end{array}$ & $\begin{array}{l}\text { Age-matched } \\
\text { control group }\end{array}$ & $\begin{array}{l}\text { Young control } \\
\text { group }\end{array}$ \\
\hline Tyrosine & $-9.1 \pm 2.2^{b, c}$ & $-6.7 \pm 1.5^{\mathrm{d}}$ & $-8.6 \pm 1.7^{\mathrm{d}}$ & $-10.7 \pm 3.5$ & $-13.7 \pm 3.9$ \\
\hline Glutamine & $-93.4 \pm 14.9^{\mathrm{d}}$ & $-113.9 \pm 59.9^{d}$ & $-98.4 \pm 18.1^{\mathrm{e}}$ & $-135.8 \pm 17.3$ & $-152.8 \pm 31.7$ \\
\hline Methionine & $-5.4 \pm 0.9$ & $-3.8 \pm 0.8^{c}$ & $-5.0 \pm 0.7$ & $-7.7 \pm 1.4$ & $-6.3 \pm 1.1$ \\
\hline Threonine & $-17.6 \pm 2.9^{\mathrm{d}}$ & $-13.7 \pm 2.9^{\mathrm{e}}$ & $-16.7 \pm 2.3^{f}$ & $-24.9 \pm 2.8$ & $-31.9 \pm 7.4$ \\
\hline Lysine & $-23.6 \pm 3.6$ & $-17.4 \pm 4.2$ & $-22.1 \pm 2.9$ & $-25.6 \pm 4.6$ & $-23.6 \pm 8.2$ \\
\hline Phenylalanine & $-9.8 \pm 1.3$ & $-8.6 \pm 2.0^{\mathrm{d}}$ & $-9.5 \pm 1.1$ & $-9.6 \pm 2.3$ & $-13.1 \pm 3.1$ \\
\hline Glycine & $-43.8 \pm 9.9^{c}$ & $-22.2 \pm 4.9^{f}$ & $-38.6 \pm 7.7^{e}$ & $-48.1 \pm 5.7$ & $-54.9 \pm 11.9$ \\
\hline Histidine & $-8.3 \pm 1.1^{\mathrm{c}}$ & $-6.0 \pm 1.4^{\mathrm{d}}$ & $-7.8 \pm 0.9^{\mathrm{d}}$ & $-10.9 \pm 1.3$ & $-12.0 \pm 2.8$ \\
\hline Alanine & $-122.7 \pm 13.4^{\mathrm{d}}$ & $-97.3 \pm 16.8^{\mathrm{d}}$ & $-116.6 \pm 11.0^{\mathrm{e}}$ & $-165.8 \pm 18.7$ & $-145.4 \pm 17.4$ \\
\hline Asparagine & $-15.6 \pm 4.2^{\mathrm{f}}$ & $-8.0 \pm 4.0^{\mathrm{f}}$ & $-13.7 \pm 3.3^{\mathrm{f}}$ & $-22.5 \pm 2.8$ & $-23.4 \pm 3.7$ \\
\hline Serine & $2.5 \pm 4.1$ & $-0.5 \pm 1.6$ & $1.8 \pm 3.1$ & $7.7 \pm 11.9$ & $-0.8 \pm 3.8$ \\
\hline Valine & $-17.0 \pm 3.6$ & $-10.0 \pm 2.5$ & $-15.2 \pm 2.8$ & $-16.9 \pm 3.3$ & $-28.1 \pm 11.6$ \\
\hline Cystine & $3.5 \pm 2.4$ & $1.6 \pm 1.2$ & $3.0 \pm 1.9$ & $4.2 \pm 4.8$ & $-3.3 \pm 2.9$ \\
\hline Isoleucine & $-8.5 \pm 1.6$ & $-6.2 \pm 1.4$ & $-8.0 \pm 1.3$ & $-7.7 \pm 1.4$ & $-11.1 \pm 3.3$ \\
\hline Leucine & $-16.2 \pm 2.9$ & $-12.4 \pm 2.9$ & $-15.3 \pm 2.3$ & $-17.4 \pm 2.6$ & $-21.9 \pm 6.9$ \\
\hline Glutamate & $55.0 \pm 6.3^{\mathrm{f}}$ & $56.3 \pm 8.0$ & $55.3 \pm 5.1^{\mathrm{f}}$ & $85.3 \pm 8.9$ & $75.4 \pm 6.1$ \\
\hline$\Sigma$ MTKYFG $^{\mathrm{h}}$ & $-109.3 \pm 17.4$ & $-72.4 \pm 15.1^{\mathrm{c}}$ & $-100.4 \pm 13.8^{c}$ & $-126.7 \pm 14.8$ & $-143.4 \pm 33.4$ \\
\hline $\mathrm{TAA}^{\mathrm{i}}$ & $-341.8 \pm 52.2$ & $-278.7 \pm 93.4^{\mathrm{d}}$ & $-326.5 \pm 45.3^{c}$ & $-420.9 \pm 56.1$ & $-466.9 \pm 111.5$ \\
\hline Glucose & $320 \pm 121^{\mathrm{g}}$ & $745 \pm 192$ & $515 \pm 966^{c}$ & $1715 \pm 368$ & NT \\
\hline Lactate & $-570 \pm 80^{d}$ & $-777 \pm 163$ & $-621 \pm 72^{\mathrm{e}}$ & $266 \pm 91$ & NT \\
\hline Free fatty acids & $-99 \pm 52^{\mathrm{d}}$ & $-95 \pm 69$ & $-98 \pm 43^{\mathrm{e}}$ & $-350 \pm 86$ & NT \\
\hline
\end{tabular}

${ }^{\mathrm{a}} \mathrm{nmol} 100 \mathrm{ml}^{-1} \mathrm{~min}^{-1}$. ${ }^{\mathrm{b}}$ Significance versus age-matched controls: ${ }^{\mathrm{c}} \mathrm{P}<0.05$; ${ }^{\mathrm{d}} \mathrm{P}<0.03$; ${ }^{\mathrm{e}} \mathrm{P}<0.01$; ${ }^{\mathrm{f}} \mathrm{P}<0.005$. ${ }^{\mathrm{g}} \mathrm{P}=0.05$; NT, not tested. ${ }^{\mathrm{h}} \mathrm{MTK}$ MFG,

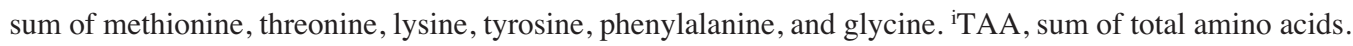

(27). Effects on proteasome activity were obtained with a set of amino acids, which included lysine and arginine but not methionine and histidine, implying that the effective amino acids were different from those reported to inhibit autophagy $(11,12,21)$.

As autophagic activity is inhibited by an increase in (certain) amino acid concentrations or by insulin stimulation, it is limited to the postabsorptive (fasted) state (reviewed in refs. 8,11,12). The absence of such inhibiting signals allows for an autophagic (and proteasomic) activity that re-establishes amino acid homeostasis, and thereby minimizes the formation of incomplete polypeptide chains. Skeletal muscle tissue of healthy human subjects shows substantial net protein catabolism after an overnight fast, i.e. during periods with low plasma amino acid and insulin levels (28-31). An increasing body of evidence suggests that the amino acidsensitive and insulin-sensitive postabsortive net protein catabolism is essentially the manifestation of autophagy (reviewed in refs. 8,11,12). Notably, at low insulin levels muscular protein catabolism was shown to be mainly mediated by the autophagic-lysosomal mechanism (32).

To evaluate the possible role of autophagy in humans, we studied the postabsorptive net protein catabolism in human skeletal muscle tissue and determined its correlation with the plasma concentrations of the distinguishing amino acids histidine, methionine, lysine, and arginine (see above). In addition, we studied the postabsorptive net protein catabolism in cancer patients at risk of cancer-related cachexia to evaluate the effect of malignant disease. The amino acid exchange rate of tyrosine across the lower extremities, which was calculated from the arterio-venous difference of plasma amino acid concentrations and the plasma flow, was used as an indirect but convenient measure of net protein synthesis or net protein catabolism in peripheral (mainly skeletal muscle) tissues of human subjects $(28,31)$.

\section{Patients and methods}

Amino acid exchange rate as a measure of net protein catabolism in the peripheral tissues of the lower extremities. The exchange rate of tyrosine across the lower extremities was taken as a measure of peripheral protein catabolism (29-32). The postabsorptive tyrosine exchange rate and the arterial free amino acid concentrations were examined in male patients with either gastrointestinal cancer $[n=47$; mean age $62 \pm 9$ (SD) years] or renal cell carcinoma ( $n=15 ; 58 \pm 8$ years), age-matched $(\mathrm{n}=33 ; 63 \pm 10$ years), and young male controls $(\mathrm{n}=42 ; 28 \pm 8$ years). Exclusion criteria were any previous cancer treatment, endocrine dysfunction, liver disease, and renal insufficiency. The cancer patients were hospitalized for curative surgery, while the age-matched control subjects had either benign abdominal diseases or angiopathies requiring 


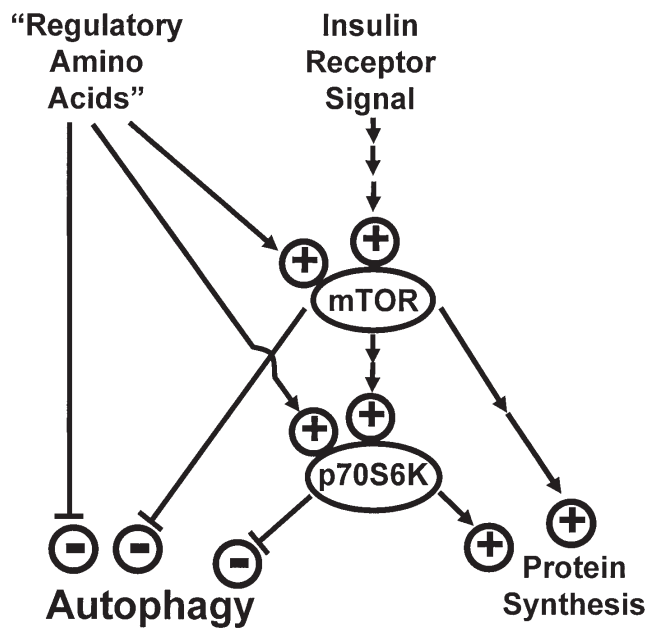

Figure 1. Inhibition of autophagic activity by 'regulatory amino acids': schematic illustration. Autophagy is negatively regulated by the mammalian target of rapamycin (mTOR) and p70S6 kinase, i.e., components of the insulin receptor signaling cascade. 'Regulatory amino acids' were shown to upregulate mTOR and p70S6 kinase, and have a direct inhibitory effect on autophagy.

elective operations. In both cancer patients and controls, body weight as percentage of optimal weight, body mass index and body cell mass as $\%$ of body weight (bioimpedance analysis) were normal. Also, standard blood chemistry data were in the normal range.

The amino acid exchange rate is derived from the difference between arterial and venous plasma amino acid concentrations (nmol ml-1) multiplied by the plasma flow $\left(\mathrm{ml} \mathrm{min}^{-1}\right)$ per tissue volume $(100 \mathrm{ml})$. Leg blood flow was quantified by venous occlusion plethysmography as described previously (33), using a Periquant 3500 device (Dr Gutmann, Eurasburg, Germany). The mean of 10 measurements was used to compute the peripheral blood flow $\left(\mathrm{ml} \mathrm{min}{ }^{-1}\right)$ per $100 \mathrm{ml}$ of tissue. Blood samples were taken from the femoral artery and vein. The femoral artery was carefully punctured after digital palpation of the groin. If necessary, an ultrasound Doppler device (Handydrop; Kranzbühler, Solingen, Germany) was also used to identify the blood vessel. The femoral vein was punctured $\sim 2 \mathrm{~cm}$ medially, and blood was taken by essentially the same procedure. All subjects were studied after an overnight fast. The exchange rates were finally calculated on the basis of the arterial and venous plasma amino acid concentrations and the blood flow according to the following equation: [(arterial concentration - venous concentration) x blood flow x (1-hematocrit)] divided by the tissue volume. The results are expressed as nanomoles $100 \mathrm{ml}^{-1} \mathrm{~min}^{-1}$. Our studies were approved by the local ethics committee and were conducted according to the principles expressed in the revised Declaration of Helsinky, 1993. Informed written consent was obtained from all participants.

Determination of plasma amino acid concentrations. For amino acid analysis, the plasma samples were deproteinized with sulfosalicylic acid and analyzed by column chromatography with a Biotronic LC 5001 instrument with Durum DC 4A (Eppendorf-Biotronic, Hamburg, Germany) as described previously (34).
Table II. Correlation between peripheral postabsorptive net protein catabolism and arterial plasma amino acid concentrations.

\begin{tabular}{|c|c|c|}
\hline \multirow[b]{2}{*}{$\begin{array}{l}\text { Amino } \\
\text { acid }^{\mathrm{a}}\end{array}$} & \multicolumn{2}{|c|}{ Correlation coefficient $r$ (Sign.) } \\
\hline & $\begin{array}{l}\text { Control } \\
\text { subjects }^{b}\end{array}$ & $\begin{array}{l}\text { Cancer } \\
\text { patients }\end{array}$ \\
\hline Y (Tyr) & $0.47^{g}$ & 0.12 NS \\
\hline $\mathrm{S}(\mathrm{Ser})$ & $0.37^{\mathrm{f}}$ & $0.00 \mathrm{NS}$ \\
\hline H (His) & $0.31^{\mathrm{e}}$ & 0.02 NS \\
\hline M (Met) & $0.34^{\mathrm{e}}$ & 0.13 NS \\
\hline F (Phe) & $0.33^{\mathrm{e}}$ & $0.17 \mathrm{NS}$ \\
\hline G (Gly) & $0.26^{c}$ & $0.06 \mathrm{NS}$ \\
\hline I (Ile) & $0.24^{\mathrm{c}}$ & $0.07 \mathrm{NS}$ \\
\hline L (Leu) & $0.23^{c}$ & 0.07 NS \\
\hline Sum of [YSHMFGIL] & $0.47^{\mathrm{g}}$ & $0.03 \mathrm{NS}$ \\
\hline V (Val) & 0.18 N.S. & $0.13 \mathrm{NS}$ \\
\hline Q (Gln) & 0.17 N.S. & $0.02 \mathrm{NS}$ \\
\hline K (Lys) & 0.17 N.S. & $0.05 \mathrm{NS}$ \\
\hline E (Glu) & 0.15 N.S. & $0.09 \mathrm{NS}$ \\
\hline $\mathrm{T}$ (Thr) & 0.14 N.S. & $0.14 \mathrm{NS}$ \\
\hline A (Ala) & 0.13 N.S. & $0.07 \mathrm{NS}$ \\
\hline $\mathrm{R}(\mathrm{Arg})$ & 0.11 N.S. & $0.13 \mathrm{NS}$ \\
\hline C (Cys) & 0.11 N.S. & $0.14 \mathrm{NS}$ \\
\hline $\mathrm{N}($ Asn) & 0.11 N.S. & $0.19 \mathrm{NS}$ \\
\hline
\end{tabular}

${ }^{\mathrm{a} O n e}$ letter code, three letter code in brackets. ${ }^{\mathrm{b}}$ Combined groups of age-matched and young control subjects. Bold letters indicate 'regulatory amino acids' identified in the rat. Significance: ${ }^{\mathrm{C}} \mathrm{P}<0.05$; ${ }^{\mathrm{d}} \mathrm{P}<0.02$; ${ }^{\mathrm{e}} \mathrm{P}<0.005$; ${ }^{\mathrm{f}}<0.002$; ${ }^{\mathrm{g}}<0.0005$; NS, not significant.

Statistical analysis. Different groups were compared by the Mann-Whitney test for independent samples. A P-value of $<0.05$ was regarded as statistically significant. Standard errors of arithmetic means were used as descriptive statistics. Correlations between parameters were described graphically by scatter plots and linear regression lines. The strength of relationship was assessed by Pearson's product-moment correlation coefficient $r$.

\section{Results}

Metabolite exchange rates in cancer patients and control subjects. The patients with gastrointestinal cancer (GIC) or renal cell carcinoma (RCC) in our study were well nourished, but their disease generally implied a risk to become cachectic. Therefore, we expected the postabsorptive protein catabolism in these patients to be as high or even higher than that of the age-matched control group. Surprisingly, we found that in these cancer patients the postabsorptive rate of protein catabolism was significantly lower than in age-matched controls as indicated by the decreased efflux of tyrosine from the lower extremities (Table I). The efflux of glutamine, threonine, 


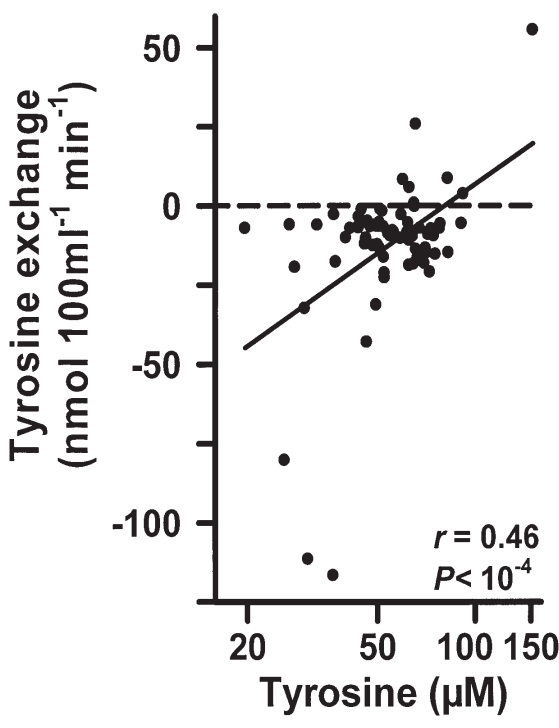

Figure 2. Correlation between postabsorptive net protein catabolism and arterial tyrosine concentration in the total group of control subjects. The regression function (solid line), correlation coefficient $r$, and significance of the correlation are shown.

glycine histidine, alanine, and asparagine as well as the uptake of glutamate were also significantly decreased in both groups of cancer patients. In the age-matched control group, the efflux of tyrosine, glutamine, threonine and glycine was, on the average, still less than in the young control group, but these differences were not statistically significant.

Incidentally it was found that the cancer patients had a decreased rate of glucose uptake, an increased efflux of lactate and a decreased efflux of fatty acids compared to agematched controls (Table I), indicating that these patients were already metabolically disturbed before the onset of clinical malnutrition.

Correlations between the postabsorptive net protein catabolism and arterial plasma amino acid concentrations indicative of autophagy. As the autophagic and proteasome-mediated mechanisms of protein catabolism were reported to be inhibited by different sets of amino acids (see Introduction), we determined whether the postabsorptive net protein catabolism may be correlated with the arterial plasma concentrations of one or the other set of amino acids. The combined data from the two control groups showed that the postabsorptive tyrosine exchange rate as our inverse indicator of net protein catabolism was significantly correlated with the arterial concentrations of the 8 amino acids tyrosine $(\mathrm{Y})$, serine $(\mathrm{S})$, histidine $(\mathrm{H})$, methionine $(\mathrm{M})$, phenylalanine $(\mathrm{F})$, glycine $(\mathrm{G})$, isoleucine (I), and leucine (L) (Table II and Fig. 2). This group included 5 of the 7 amino acids that had previously been identified as 'regulatory amino acids' in the control of autophagic activity in the rat. In contrast, this group did not include the amino acids, arginine and lysine, which have been implicated in the regulation of the proteasome-mediated protein catabolism (see Introduction). Proline, tryptophan, and cysteine were not detected in our amino acid analysis. Other amino acids showed no significant correlation with the tyrosine exchange rate.

Also in the two groups of cancer patients, we observed no significant correlation among the tyrosine exchange rates

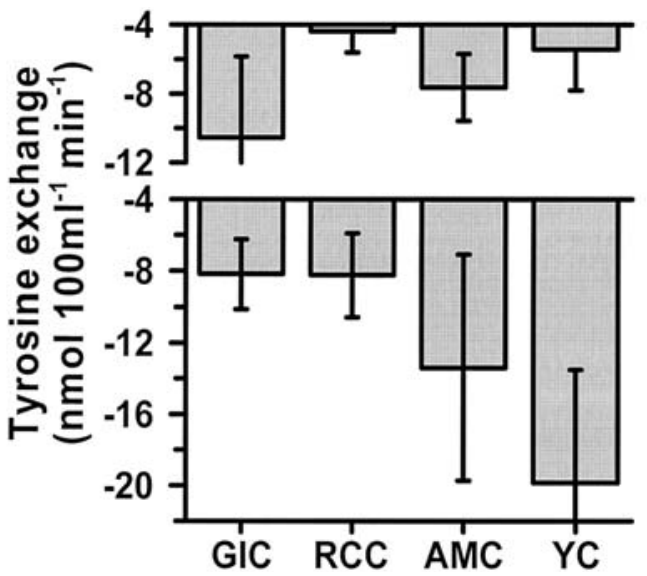

Figure 3. Postabsorptive net protein catabolism in subjects with high and low arterial [YSHMFGIL] levels. Tyrosine exchange rates are given for subjects with [YSHMFGIL] > median (upper panel) and [YSHMFGIL] $<$ median (lower panel). GIC, gastrointestinal cancer patients; RCC, patients with renal cell carcinoma; AMC, age-matched control subjects; and $\mathrm{YC}$, young control subjects

and amino acid concentrations (Table II). A more detailed analysis showed that subjects with high(er than median) [YSHMFGIL] values had, on the average, similar and relatively small tyrosine exchange rates in all four groups of patients and controls under test (Fig. 3, upper panel). Major differences between the four groups of subjects were only seen among the subsets with low(er than median) [YSHMFGIL] levels (Fig. 3, lower panel).

\section{Discussion}

In healthy subjects we found significant correlations between postabsorptive muscular amino acid exchange rates and the arterial plasma concentrations of 5 of the 7 amino acids (Table II) that have been identified to regulate autophagy in the rat $(11,12,21)$. This may indicate a role of autophagy in the net protein degradation of skeletal muscle under conditions of low insulin concentrations. However, as the major portion of the variability in net protein degradation remained unexplained by these amino acids, our data allow no conclusion of the separate contribution of autophagic and proteasomic protein degradation under the postabsorptive conditions, as drawn earlier by others (32). As a methodological limitation to this study, the amino acid exchange rate across assesses a net effect, i.e. it does not separate protein synthesis from degradation.

However, as an unexpected but important finding, both groups of cancer patients showed, on the average, a significantly lower postabsorptive net protein catabolism than the two control groups. Together with a decrease in tyrosine exchange rate, there was also a significant decrease in the exchange rates of several other amino acids, including amino acids that are not metabolized in muscle tissue $(35,36)$. Moreover, the cancer patients showed no significant correlation between the tyrosine exchange rate and the arterial amino acid concentrations. The fact that both groups of patients showed practically normal (and relatively low) tyrosine exchange rates at high arterial [YSHMFGIL] levels and no substantial increase in protein catabolism at low [YSHMFGIL] 
levels (Fig. 3) may suggest that in these patients the amino acid-sensitivity component of protein catabolism (autophagy) may be disturbed.

These cancer patients were well nourished, but the metabolic dysregulation in malignant diseases is known to start well before overt weight loss. As the arterial concentrations of the 'regulatory amino acids' in the two groups of cancer patients were not markedly higher than those of the control groups (data not shown), it is suggested that autophagy was inhibited in these patients by a mechanism other than the inhibitory signal from 'regulatory amino acids'.

The significantly lower glucose exchange rate in cancer patients compared to age-matched controls points at a possible muscular insulin resistance. As plasma insulin levels were not assessed, a separate inhibiting effect of increased insulin on autophagy or proteasome activity via Akt $(15,16)$ cannot be ruled out.

Any failure to express autophagic activity at times of amino acid starvation and low insulin concentrations is likely to impair the homeostatic control of free amino acid concentrations. If certain amino acids become limiting in protein synthesis, incomplete and unfolded polypeptide chains are likely to accumulate. This may be related to the fact that cancer patients were found to have an increased rate of proteasomal protein catabolism as abnormal polypeptides are typically degraded by the ubiquitin/proteasome-dependent proteolytic mechanism (37-40). However, the causative mechanisms are still unknown.

\section{Acknowledgements}

We thank Dr L. Edler for assistance in the statistical analysis, Dr R. Breitkreutz for help, Mr H. Lips for expert technical assistance and clinical data management, and Mrs. I. Fryson for assistance in the preparation of the study.

\section{References}

1. Reggiori F and Klionsky DJ: Autophagy in the eukaryotic cell, Eukaryot. Cell 1: 11-21,2002

2. Wang C-W and Klionsky DJ: The molecular mechanism of autophagy. Mol Med 9: 65-76, 2003.

3. Melendez A, Talloczy Z, Seaman M, Eskelinen EL, Hall DH and Levine B: Autophagy genes are essential for dauer development and life-span extension in C. elegans. Science 301: 1387-1391, 2003

4. Tsukada M and Ohsumi Y: Isolation and characterization of autophagy-defective mutants of Saccharomyces cerevisiae. FEBS Lett 333: 169-174, 1993

5. Otto GP, Wu MY, Kazgan N, Anderson OR and Kessin RH: Macroautophagy is required for multicellular development of the social amoeba Dictyostelium discoideum. J Biol Chem 278: 17636-17645, 2003.

6. Klionsky DJ and Emr SD: Autophagy as a regulated pathway of cellular degradation. Science 290: 1717-1721, 2000.

7. Elmore SP, Qian T, Grissom SF and Lemasters JJ: The mitochondrial permeability transition initiates autophagy in rat hepatocytes. FASEB J 00: 2286-2287, 2001.

8. Dröge W: Autophagy and aging - importance of amino acid levels. Mech Ageing Dev 125: 161-168, 2003.

9. Terman A, Dalen H, Eaton JW, Neuzil J and Brunk UT: Mitochondrial recycling and aging of cardiac myocytes: the role of autophagocytosis. Exp Gerontol 38: 863-876, 2003.

10. Bergamini E, Cavallini A and Gori DZ: The anti-ageing effects of caloric restriction may involve stimulation of macroautophagy and lysosomal degradation, and can be intensified pharmacologically. Biomed Pharmacother 57: 203-208, 2003.
11. Mortimore GE and Pösö AR: Intracellular protein catabolism and its control during nutrient deprivation and supply. Annu Rev Nutr 7: 539-564, 1987.

12. Mortimore GE and Pösö AR: The lysosomal pathway of intracellular proteolysis in liver: regulation by amino acids. Adv Enzyme Regul 25: 257-276, 1986.

13. Woodside KH and Mortimore GE: Suppression of protein turnover by amino acids in the perfused rat liver. J Biol Chem 247: 6474-6481, 1972.

14. Mortimore GE and Schworer CM: Induction of autophagy by amino-acid deprivation in perfused rat liver. Nature 270: 174-176, 1977.

15. Kanazawa T, Taneike I, Akaishi R, Yoshizawa F, Furuya N, Fujimura S and Kadowaki M: Amino acids and insulin control autophagic proteolysis through different signaling pathways in relation to mTOR in isolated rat hepatocytes. J Biol Chem 279: 8452-8459, 2004

16. Fulks RM, Li JB and Goldberg AL: Effects of insulin, glucose, and amino acids on protein turnover in rat diaphragm. J Biol Chem 250: 290-298, 1975

17. Li JB and Jefferson LS: Influence of amino acid availability on protein turnover in perfused skeletal muscle. Biochim Biophys Acta 544: 351-359, 1978.

18. Buse MG and Reid SS: Leucine: A possible regulator of protein turnover in muscle. J Clin Invest 56: 1250-1261, 1975.

19. Chua B, Siehl DL and Morgan HE: Effect of leucine and metabolites of branched chain amino acids on protein turnover in heart. J Biol Chem 254: 8358-8362, 1979.

20. Mordier S, Deval C, Béchet D, Tassa A and Ferrara M: Leucine limitation induces autophagy and activation of lysosomedependent proteolysis in $\mathrm{C} 2 \mathrm{C} 12$ myotubes through a mammalian target of rapamycin-independent signaling pathway. J Biol Chem 275: 29900-29906, 2000.

21. Pösö AR, Wert JJ and Mortimore GE: Multifunctional control by amino acids of deprivation-induced proteolysis in liver. J Biol Chem 257: 12114-12120, 1982.

22. Tallóczy Z, Jiang W, Virgin IV HW, Leib DA, Scheuner D, Kaufmann RJ, Eskelinen EL and Levine B: Regulation of starvation- and virus-induced autophagy by the eIF $2 \alpha$ kinase signaling pathway. Proc Natl Acad Sci USA 99: 190-195, 2002.

23. Tremblay $\mathrm{F}$ and Marette A: Amino acid and insulin signaling via the $\mathrm{mTOR} / \mathrm{p} 70$ S6 kinase pathway. J Biol Chem 276: 38052-38060, 2001

24. Fingar DC and Blenis J: Target of rapamycin (TOR): an integrator of nutrient and growth factor signals and coordinator of cell growth and cell cycle progression. Oncogene 23: 3151-3171, 2004.

25. Krause U, Bertrand L, Maisin L, Rosa M and Hue L: Signalling pathways and combinatory effects of insulin and amino acids in isolated rat hepatocytes. Eur J Biochem 269: 3742-3750, 2002.

26. Blommaart EFC, Luiken JJFP, Blommaart PJE, Meijer AJ and van Woerkom GM: Phosphorylation of ribosomal protein S6 is inhibitory for autophagy in isolated rat hepatocytes. J Biol Chem 270: 2320-2326, 1995.

27. Hamel FG, Upward JL, Siford GL and Duckworth WC: Inhibition of proteasome activity by selected amino acids. Metabolism 52: 810-814, 2003.

28. London DR, Foley TH and Webb CG: Evidence for the release of individual amino acids from the resting human forearm. Nature 208: 588-589, 1965

29. Biolo G, Fleming RYD, Maggi SP and Wolfe RR: Transmembrane transport and intracellular kinetics of amino acids in human skeletal muscle. Am J Physiol 268: E75-E84, 1995.

30. Volpi E, Ferrando AA, Yeckel CW, Tipton KD and Wolfe RR: Exogenous amino acids stimulate net muscle protein synthesis in the elderly. J Clin Invest 101: 2000-2007, 1998.

31. Svanberg E, Moller-Loswick AC, Matthews DE, Korner U, Andersson M and Lundholm K: The role of glucose, long-chain triglycerides and amino acids for promotion of amino acid balance across peripheral tissues in man. Clin Physiol 19: 311-320, 1999.

32. Dice JF: Molecular determinants of protein half-lives in eukaryotic cells. FASEB J 1: 349-356, 1987.

33. Barbay K and Barbay P: Ein neuer Plethysmograph zur Messung der Extremitäten-durchblutung. Z Kreislaufforsch 52: 1129-1140, 1963.

34. Kinscherf R, Hack V, Fischbach T, Friedmann B, Weiss C, Edler L, Bärtsch P and Dröge W: Low plasma glutamine in combination with high glutamate levels indicate risk for loss of body cell mass in healthy individuals: the effect of N-acetylcysteine. J Mol Med 74: 393-400, 1996. 
35. van Hall G, Saltin B and Wagenmakers AJM: Muscle protein degradation and amino acid metabolism during prolonged kneeextensor exercise in humans. Clin Sci 97: 557-567, 1999.

36. Goldberg AL and Chang TW: Regulation and significance of amino acid metabolism in skeletal muscle. Fed Proc Am Soc Exp Biol 37: 2301-2307, 1978.

37. Ciechanover A: The ubiquitin-proteasome proteolytic pathway. Cell 79: 13-21, 1994
38. Goldberg AL, Akopian TN, Kisselev AF, Lee DH and Rohrwild M: New Insights into the mechanisms and importance of the proteasome in intracellular protein degradation. Biol Chem 378: 131-140, 1997

39. Spike CA and Strome S: Germ plasm: Protein degradation in the soma. Curr Biol 13: R837-R839, 2003.

40. Lee A-H, Iwakoshi NN, Anderson KC and Glimcher LH: Proteasome inhibitors disrupt the unfolded protein response in myeloma cells. Proc Natl Acad Sci USA 100: 9946-9951, 2003. 